\title{
Cigarette Smoking among Male Teenagers in Malaysia - A Narrative Review
}

\author{
R. III P. DIOSO
}

\begin{abstract}
.This narrative review of a contemporary healthcare issue focuses on strategies and healthcare initiatives to curtail the increasing prevalence of active cigarette smoking among male teenagers in Malaysia - a mission of the Malaysian Millennium Development Goal and the United Nations Development Programmes on all health sectors. This narrative review analysed global and Malaysian views on cigarette smoking.
\end{abstract}

Key words: Healthcare; strategies; initiatives; curtail cigarette smoking; male teenagers; Malaysia

This narrative review aims to analyse the impact of active cigarette-smoking as a contemporary healthcare issue in Malaysia. Another aim of this review is to identify the best strategy and healthcare initiative to curtail the prevalence of cigarette-smoking in all health sectors.

According to World Health Organisation (WHO 2012), cigarette smoking is the action or habit of inhaling and exhaling the smoke of cigarettes. Smoking in general can attribute to a lot of physical illnesses and diseases; hence, it distracts the mental, psychological and social capacity of an individual to adapt (Kiechl et al. 2002; Lim et al. 2010; Isohanni et al. 2006; Lee et al. 2005; Naing et al. 2004; WHO 2012; Ferrante et al. 2010). Specifically, active cigarette-smoking disturbs a person's well being (Mohide, 1988; Kiechl et al. 2002) because it weakens their heart, brains and lungs.

There are two types of cigarette smoking. The active smoking or first-hand smoking is known as the first type defined as, the act of inhaling the smoke of cigarettes from one's self (Kiechl et al. 2002; Lim et al. 2010; Isohanni et al. 2006; Lee et al. 2005; Naing et al. 2004; WHO, 2012; Ferrante et al. 2010). The second type is called the second-hand smoking or passive smoking defined as, the exposure to environmental cigarette smoke (Kiechl et al. 2002; Lim et al. 2010).

\section{Search Strategy}

Literatures reviewed were from years 2000 2014. Limitations were set on databases to English language. Key words used were: Malaysian male teenage cigarette smokers; active cigarette smoking habits; prevalence of male cigarette smoking in Malaysia and worldwide; and severity of the prevalence of active cigarette smoking among male teenagers, that were entered as text in search engines such as Researchgate, Google Scholars and Cochrane databases with abstracts and full texts.

\section{Methods of Review}

A critiquing framework (Figure 1) was used to analyse the literatures selected for this review since it was designed with nine categories

Lincoln University College, Block A, Lot 1, Mayang Plaza, 1 Jalan SS 26/1, Taman Mayang, 47301 Petaling Jaya, Malaysia E-mail: duke@lincoln.edu.my 
Common features of:

\begin{tabular}{lll}
\hline Quantitative & Qualitative \\
\hline Research design & Philosophical background \\
Experimental hypothesis & Research design \\
Operational definitions & Concepts \\
Population & Context \\
Sample & Sample \\
Sampling & Sampling \\
Validity/reliability of data & Auditability of data \\
Data analysis & Credibility/comfirmability of data analysis \\
Generalizability & Transferability \\
\hline
\end{tabular}

Figure 1. Critiquing framework (Couglan et al. 2007; Ryan et al. 2007).

as guides to conveniently aid the reviewer to make sense of evidence from clinical trials and theories (Polit \& Beck 2011; Ryan et al. 2007; Couglan et al. 2007).

\section{RESULT}

\section{Worldwide Prevalence of Cigarette Smoking}

A World Health Organisation (WHO, 2012) study has showed a total of 43 trillion active cigarette smokers all over the world (Figure 2). They are found on the regions of America (11\%), Europe (24\%), East Mediterranean (6\%), Western Pacific (48\%), Africa (3\%) and Southeast Asia (8\%) (WHO 2012). It was also found that from year 2000 to 2010, the global severity of cigarette smoking by male teenagers increased over 100 times with an average of 865 pieces of cigarettes or 43 packs per day worldwide.

In Malaysia, a ten-year survey was conducted by a global organisation called Global Adult Tobacco Survey (GATS 2012) and found that $43.9 \%$ of cigarette smokers

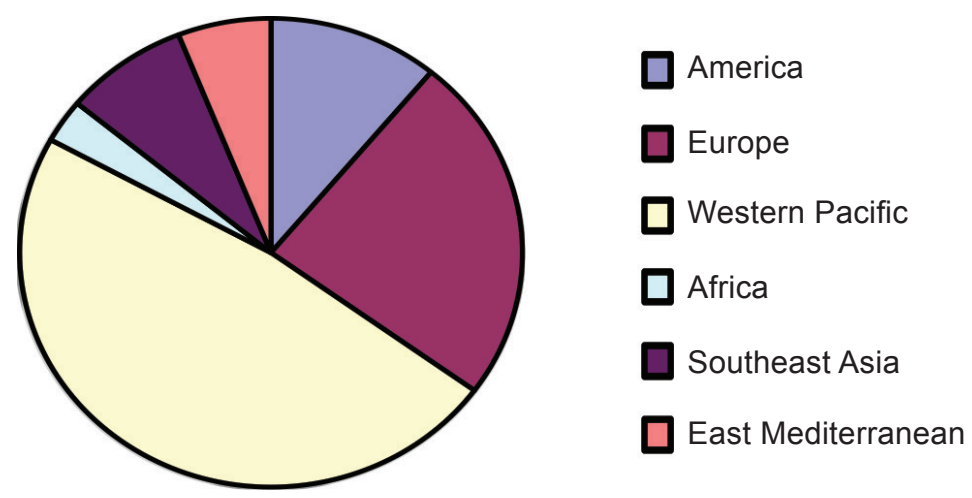

Figure 2. Global illustration from six regions where cigarettes are smoked for their whole life from a total population of 43 trillion. 
were male teenagers. Active teenage cigarette smokers in Malaysia smoke on a daily basis, as surveyed by GATS (2012), are local citizens, transient visitors from foreign countries, regular male teenage tourists and children of foreign immigrants.

Another study was done by Lim et al. (2010) for 1180 teenage students in comparison and in contrast with the GATS (2012) survey, with a response rate of $94.7 \%(1117)$. Of the 1117 respondents, $705(63.1 \%)$ are former smokers and 397 (35.5\%) are current smokers. Among the current smokers, 36 (9.1\%) was daily smokers, $48(12.1 \%)$ smoke once every two days, $131(33.0 \%)$ smoke once or twice a week and the rest smoke once a week (Lim et al., 2010; WHO-MOH 2012).

The GATS survey in comparison with the studies done by Lim et al. (2010) was found to be higher as prevalent in male adolescents' cigarette smoking. It was also higher compared with what is reported by the MOH (2006) spanning from the city of Kota Bharu in the state of Kelantan to the city of Petaling Jaya in the state of Selangor (Afiah et al. 2006).

The prevalence of cigarette smoking in Malaysia, complicated by gender, race, ethnicity and culture, particularly influenced male teenage cigarette smokers who continue the chain of influence among their peers (Wakefield et al. 2000; Naing et al. 2004; Poland et al. 2006).

\section{DISCUSSION}

Influence is a determinant of health that increases the prevalence of cigarette smoking among male teenagers (Child \& Wi 2010; Ferrante et al. 2010; Watsen et al. 2010).

Teenage boys are perceived to influence their peers of the same gender (Lim et al. 2010; Afiah 2006; Ferrante et al. 2010).
The perception of a relief from stress after so much of studying and thinking makes teenage boys influence each other (Isohanni et al. 2006; Child et al. 2010; Jeanfreau et al. 2010; Lee et al. 2005).

Aside from gender, the successful lifestyle coming from a specific race, ethnicity and culture are also influential (Isohanni et al. 2006; Gonseth et al. 2012; Poland et al. 2006). Eventually these become influential to young boys making them actively smoke cigarettes as a part of thier lifestyle.

Lastly, cigarettes used for entertainment influences male teenagers to actively smoke cigarette smoking (Isohanni et al. 2006; Afiah et al. 2006). According to Poland et al. (2006), active cigarette smoking entertains the social appetite and social life. It is also entertaining when young boys in Malaysia tend to show off their ability to buy cigarettes to make their social status higher as influenced by adults (Lim et al. 2010; Naing et al. 2004).

These health determinants were evaluated using a system called health screening. Health screening is done in public and private schools in Malaysia by GATS (2012) and MOH (2007). High school young boys ages 13-19 years old were interviewed with survey forms to know their perceptions regarding smoking cigarettes (WHO-MOH 2012).

Health screening also involved organisations to visit hospitals and to analyse statistics on average teenage adolescents confinement taken yearly with collaborations from the MOH (Gabing 2010). A schedule of yearly statistical presentation among other healthcare institutions and hospitals gather together in a certain place to present findings or analyse statistical data collected from hospital confinement, mortality and discharged patients with presenting illnesses and diseases as caused by cigarette smoking (MOH 2007). 
Another form of health screening is being done annually on a continuous research conducted by Disease Control Division $(\mathrm{MOH}$ 2007).

The survey results found that active cigarette smokers among teenage boys are divided into current smokers, daily smokers, occasional heavy smokers and former daily (not more than 5 years ago) smokers (Lim et al. 2010; GATS 2012; MOH 2007). This impacts the MOH's healthcare delivery system since teenagers' health are at risk if they are influenced to become active cigarette smokers (Lim et al. 2010; WHO 2008; Lee et al. 2005). There is a need to ensure that the Malaysian government invests strategies to control or decrease the number of teenagers who smoke (WHO-MOH 2012).

\section{Implications to Health Promotions}

WHO-MOH (2012) implemented varieties of programmes to control cigarette smoking with an aim to reduce its consumption.

One of its programmes is to promote pictorial health warnings on cigarette packs with a general message that says Smoking Causes Harm to Health (MOH 2008). These photos were further enhanced when other researchers suggested showing pictures of cancerous organs i.e. throat, neck, lung, mouth and brain cancers (Azam \& Maizura 2004). Another illustration of these pictures suggested by Azam and Maizura (2004) used heart failures with ischemic tissues, chronic obstructive pulmonary diseases, veins with plaques as adopted from anatomy and physiology books (Tortora \& Derrickson 2010).

Another programme implemented by the Malaysian MOH (2007/2008) launched a campaign called Say No in 2004. This campaign was first initiated by the Southeast Asian Tobacco Control Alliance and was soon adopted by the Malaysians in 2008. The $\mathrm{MOH}$ used teenagers to rally and march across main roads and all over national highways of Malaysia carrying a banner with printed words saying Tak nak (Say No) (MOH 2008). This kind of campaign may stimulate the minds of influenced teenagers that it is not good to smoke (MacFarlane et al. 2010) and that egos can be boosted in other ways that are non-health hazard related $(\mathrm{MOH} 2008)$.

Another campaign implemented by the Malaysian MOH (2008/2006) was adopted from the policies of the World Bank (Lewit et al. 1981) recommending governments worldwide to introduce a dedicated tax on tobacco products. Teenagers, as anticipated, cannot afford to buy cigarettes in their youth (Wakefield et al. 2000). However, some of the school age students in Malaysia who cannot afford a pack of cigarettes will buy a single stick (Lim et al. 2010), that is allowed by some states like Sabah and Sarawak (MOH 2006).

The control of the habit of cigarette smoking was not strong enough using taxes, that was why another policy to make the strategy stronger was initiated.

The Malayasian MOH (2006/2007) banned certain areas in Malaysia from smoking and used signboards with written warnings for smokers such as smoke-free area. The private and government owned institutions in Malaysia supported this strategy by imposing a fine on smokers caught by security personnel smoking within the 'no smoking' zone. Over $80 \%$ of institutions in Malaysia supported this campaign using a total cigarette smoking ban indoors with air-conditioners such as restaurants, hospitals and educational institutions (MOH 2006/2007). This is also practiced worldwide as indoorprivate institutions placed a smoking area that is located in a small location so that lesser people will smoke (Wakefield et al. 2000). 


\section{Analysis}

The identified strategies on health promotions and illness preventions against active cigarette smoking acquired a critical understanding and demonstrated a commitment to apply professional values in complex healthcare situations. Active cigarette smoking in a Malaysia is a contemporary healthcare issue that needs to be identified.

This narrative review is for future reference among healthcare professionals to be vigilant in preventing illnesses or promoting measures and procedures to improve a person's wellbeing (Olla 2006; Mohide 1988).

The target of the Malaysian Millennium Development Goal (MMDG) (WHO-MOH 2012) in the health sector is to curtial the threats of cigarette smoking that impacts on teenage boys in Malaysia. Teenage active cigarette smokers influence other teenagers to smoke cigarettes (Lim et al. 2010; Watsen et al. 2010).

United Nations Development Programmes (UNDP) (2011) recommended to healthcare professionals a multi-disciplinary approach to encourarge individuals to join campaigns against cigarette smoking (WHO 2012) using healthcare intitiatives.

Campaigns must endeavour to curtail chain smoking as a health hazard (Isohanni et al. 2010; Ferrante et al. 2010). Chain smokers among male teenagers can acquire diseases and illnesses that are morbid and very difficult to cure when they grow older (Kiechl et al. 2002; Tortora \& Derrickson 2010).

This is the wider health threat that impacts teenage boys who smokes cigarettes (Lim et al. 2010) especially if their smokes affects their family members or peers who are confirmed to be pregnant or ill - extending to the severity of second-hand smoking.

\section{CONCLUSION}

The prevalence of active and second-hand cigarette smoking among male teenagers in Malaysia should be prevented.

It is therefore concluded that in order for healthcare initiatives, such as MMDG and UNDP, to overcome problems of cigarette smoking, a good strategy is important especially on campaigning preventive measures against the threats of chain cigarette smoking. In addition, an awareness campaign should emphasise on preventing teenagers' influential capabilities to non-cigarette smokers.

Active and second-hand cigarette smoking can cause chronic and/or incurable physiologic imbalances. That is why prevention is better than cure.

Date of submission: July 2014

Date of acceptance: November 2014

\section{REFERENCES}

Afiah, MZ, Hejar, AR, Kulanthayan, KC, Fadhilah, J \& Law, TH 2006, 'Prevalence of smoking and drinking habits among form six students in Petaling district, Selangor', Medical Journal Malaysia, vol. 61, no. 1, pp. 41-47.

Azam, A \& Maizurah, O 2004, 'Cigarette Packages: how far the visual messages influence youth', in The 7th Asia Pacific Conference on Tobacco or Health, MOH, Malaysia.

Child, E \& Wi, HD 2010, 'Effects of acute psychosocial stress on cigarette craving and smoking', Nicotine and Tobacco Research, vol. 12, no. 4, pp. 449-453.

Coughlan, M, Cronin, P \& Ryan, F 2007, 'Step-bystep guide to critiquing research methodologies, Part 1: quantitative Research', British Journal of Nursing, vol. 16, no. 1, pp. 658-663.

Ferrante, M, Fiore, M, Lean, L, Costantidines, F, Castaing, M, Fallico, R, Sciacca, S \& Modonutti, GB 2010, 'Age of smoking initiation, tobacco habits and risk perception among primary, middle and high school students in Southern Italy', 
Italian Journal of Public Health, vol. 7, no. 3, pp. 262-267.

Gabing, F 2010, 'The Sabah perspective: health promotion initiatives in rural health', The Malaysian Journal of Nursing. A Journal for the Healthcare and Nursing Community, vol. 1, no. 3, pp. 21-24.

Global Adult Tobacco Survey 2012, GATS collaborative group: question-by-question specifications, Version 2.0, Centers for Disease Control and Prevention, Atlanta.

Gonseth, S, Sadowski, IJ, Diethelm, PA, Barras, V \& Cermiz, J 2012, 'The tobacco industry's past role in weight control related to smoking', The European Journal of Public Health Advance, vol. 22, no. 2, pp. 234-237.

Isohanni, M, Moilanen, I \& Rantakallio, P 2006, 'Determinants of teenage smoking, with special reference to non-standard family background', British Journal of Addiction, vol. 86, no. 4, pp. 391-398.

Jeanfreau, S, Porche, D \& Lee, OD 2010, 'Determinants of health: a framework for advanced health assessment: men's health', The Journal for Nurse Practitioners, vol. 6, no. 3, pp. 226-227.

Kiechl, S, Werner, P, Egger, G, Oberhollenzer, F, Mayr, G, Xu, Q, Poewe, W \& Willeit, J 2002, 'Active and passive smoking, chronic infections, and the risk of carotid atherosclerosis prospective results from the Bruneck study', Journal of the American Heart Association, vol. 33, pp. 2170-2176.

Naing, NN , Zulkifli, A, Razlan, M, Farique Rizal, AH, Haslan, G \& Mohd Hilmi, AB 2004, 'Factor related to smoking habit of male adolescents', Tobacco Induced Diseases, vol. 2, no. 3, pp. 133-140.

Lee, LK, Paul, CYC, Kam, CW \& Jagmohni, K 2005, 'Smoking among secondary school students in Negeri Sembilan, Malaysia', Asia Pacific Journal of Public Health, vol. 17, no. 2, pp. 130-136.

Lewit, EM, Coate, D \& Grossman, M 1981, 'The effects of government regulation on teenage smoking', Journal of Law and Economics, vol. 24, no. 3, pp. 273-298.

Lim, KH, Sumarni, MG, Kee, CC, Norhamimah, A, Wan Rozita, WM \& Amal, NM 2010 ,
'Prevalence, smoking habit and factors related to smoking and nicotine addiction among lower secondary school male students in Kota Tinggi District, Johor, Malaysia', Malaysian Journal of Public Health Medicine, vol. 10, no. 1, pp. 28-37.

MacFrlane, K, Paynter, J \& Arroll, B 2011, 'Tax as a motivating factor to make a quit attempt from smoking', Journal of Primary Health Care, vol. 3, no. 4, pp. 283-288.

Ministry of Health 2008, Food Act 1983, Control of tobacco product (amendment) regulations, Malaysia, $\mathrm{MOH}$.

Ministry of Health 2007, Disease Control Division, Clinical Practice Guidelines. Treatment of tobacco smoking and dependence, $\mathrm{MOH}, \mathrm{KL}$, Malaysia.

Ministry of Health Malaysia 2006, Smoking: the third national health and morbidity survey, 2006, Institute of Public Health, Malaysia.

Mohide, EA, Torrance, GW, Streiner, DL, Pringle, DM \& Gilbert, R 1988, 'Measuring the wellbeing of family caregivers using the time trade-off technique', Journal of Clinical Epidemiology, vol. 41, no. 5, pp. 475-482.

Naing, NN, Zulkifli, A, Razlan, M, Farique Rizal, AH, Haslan, G \& Mohd Hilmi, AB 2004, 'Factor related to smoking habit of male adolescents', Tobacco Induced Diseases, vol. 2, no, 3, pp. 133-140.

Olla, P 2006, Book review: handbook of informatics for nurses and health care professionals, 3rd edn, International Journal of Healthcare Information Systems and Informatics, vol. 1, no. 3, pp. 77-79.

Poland, B, Frohlich, K, Haines, RJ, Mykhalorskiy, E, Rock, M \& Sparkus, R 2006, 'The social context of smoking: the next frontier in tobacco control', Tobacco Control, vol. 15, pp. 59-63.

Polit, DF \& Beck, C T 2011, Nursing research: generating and assessing evidence for nursing practice, 9th edn, Lippincott Williams \& Wilkins, USA.

Ryan, F, Coughlan, M \& Cronin, P 2007, 'Step-bystep guide to critiquing research methodologies, part 2: qualitative research', British Journal of Nursing, vol. 16, no. 2, pp. 738-744.

Tortora, G \& Derrickson, B 2010, Essentials of anatomy and physiology (Malaysian student version), 8th edn, John Wiley and Sons, Asia. 
United Nations Development Programmes 2011, Malaysian development goal, UNDP, Geneva.

Wakefield, M, Frank, J, Kaufman, NJ, Orleans, CT, Barker, D \& Ruel, E 2000, 'Effect of restrictions on smoking at home, at school, and in public places on teenage smoking: cross sectional study', British Medical Journal, vol. 321, pp. 623-630.

Watsen, D, Bullen, C, Glover, M, McRobbie, H, Parag, V \& Walker, N 2010, 'Impact on quit attempt of mailed general practitioner 'brief advice' letters plus nicotine replacement therapy vouchers', Journal of Primary Health Care, vol. 2, no. 1, pp. 4-10.

World Health Organization-Ministry of Health, 2012, World health organization-Malaysia: country cooperative strategy 2009-2013, WHO, Geneva.

World Health Organization 2012, World health report on the global tobacco epidemic, 2008: the MPOWER package, WHO, Geneva. 